\title{
Concentrations of specific unsaturated fatty acids in semitendinosus muscle of early and late maturing heifer calves offered concentrates containing either safflower oil or ruminally- protected fish oil while at pasture
}

P.G. Dunne ${ }^{1}$, F.J. Monahan ${ }^{2}$, K.J. Shingfield ${ }^{3}$, A.P. Moloney ${ }^{1}$

${ }^{1}$ Teagasc, Grange Beef Research Centre, Dunsany, Co. Meath, Ireland, ${ }^{2}$ School of Agriculture, Food Science \& Veterinary Medicine, College of Life Sciences, University College Dublin, Dublin 4, Ireland, ${ }^{3}$ MTT Agrifood Research Finland, Animal Production Research, Jokioinen, FIN 31600, Finland

Email: peter.dunne@teagasc.ie

Introduction There is increasing evidence that diet has a major role in the development of chronic diseases in humans. Ruminant derived foods are a major source of fat in the human diet and therefore there is increasing interest in enhancing the nutritional value of these foods to improve long-term human health. Beef from cattle reared on grass is known to contain appreciable concentrations of fatty acids that exhibit positive effects including oleic acid (OA, cis-9 18:1), the long chain n-3 fatty acids eicosapentaenoic acid (EPA, 20:5n-3) and docosahexaenoic acid (DHA, 22:6n-3) and cis-9, trans-11 conjugated linoleic acid (CLA) (Nuernberg et al., 2002). Supplementation with plant oils or marine lipids can be used to enhance tissue CLA concentrations while significant enrichment of EPA and DHA in beef requires the use of rumen protected fish oil due to the extensive metabolism of long chain n-3 fatty acids in the rumen. This experiment was designed to examine the potential of concentrate supplements containing safflower oil (SAFF) as a rich source of 18:2n-6 (Boles et al., 2005; Dinius et al., 1974) or rumen protected fish oil (RPFO) to increase muscle concentrations of cis-9, trans-11 CLA and n-3 LC-PUFA, respectively, in grazing heifer calves.

Materials and methods Ninety-six 4-month old heifer calves, of which 48 were early-maturing Aberdeen Angus $\times$ Friesian (AAF) and 48 were late-maturing Belgian Blue $\times$ Friesian (BBF) were recruited to the experiment and randomly assigned to a control (grazing only) treatment (CONT), or supplementation with concentrates containing either SAFF or a proprietary RPFO supplement (920g dry matter (DM)/kg, 302g lipid/kg DM, 3.47g EPA/100g and 5.74g DHA/100g) . Biopsy samples of semitendinosus muscle were recovered after 4 months on diet using a spring-loaded biopsy gun (Biotech PPB-U, Nitra, Slovakia) following local administration of adrenacaine (Norbrook Laboratories, Ltd., Newry, BT35 6JP, Northern Ireland) and stored under $\mathrm{N}_{2}$ at $-20^{\circ} \mathrm{C}$ until analysed. Extraction of tissue lipids and conversion to fatty acid methyl esters (FAME) was performed according to standard procedures (Noci et al., 2005). The composition of FAME and determination of tissue fatty acid content was determined by GC-FID using a Varian CP3800 chromatograph with a CP8400 autosampler and employing a CP-Sil 88 cyanopropyl fused capillary column $(100 \mathrm{~m} \times 0.25 \mathrm{~mm}$ i.d. $\times 0.2 \mu \mathrm{m}$ film thickness, Chrompack, Middelburg, The Netherlands) with $\mathrm{H}_{2}$ as carrier gas (Shingfield et al., 2003). Fatty acid concentrations ( $\mathrm{mg} / 100 \mathrm{~g}$ muscle) were calculated according to the formula of Golay et al. (2006). Data were subjected to Analysis of Variance for a randomised block design with a 2 (breeds, B) $\times 3$ (diets, D) factorial arrangement of treatments.

Results Concentrations (mg/100g muscle) of EPA, DHA and cis-9, trans-11 CLA in semitendinosus muscle are presented in Table 1. There was no effect ( $\mathrm{P}>0.05)$ of breed on EPA (15.42 v. 17.28 for AAF and BBF, respectively; $\mathrm{SED}=1.641)$ or DHA (6.07 v 6.61 for AAF and BBF, respectively; $S E D=0.505)$ concentrations. For EPA, there was no difference between CONT and SAFF, while RPFO resulted in a significant $(\mathrm{P}<0.001, \mathrm{SED}=2.010)$ 3-fold enrichment. Supplements of RPFO also resulted in significantly $(\mathrm{P}<0.001, \mathrm{SED}=1.229)$ higher concentrations of DHA compared with CONT or SAFF. There was no effect of breed $(\mathrm{P}=0.159, \mathrm{SED}=0.671)$ or $\operatorname{diet}(\mathrm{P}=0.386, \mathrm{SED}=0.822)$ on muscle cis -9 , trans-11 CLA content.

Table 1 Concentrations (mg/100g muscle) of EPA, DHA and cis-9, trans-11 CLA in semitendinosus muscle from heifer calves

\begin{tabular}{|c|c|c|c|c|c|c|c|c|c|}
\hline Fatty acid & & AAF & & & $\mathrm{BBF}$ & & & $\mathrm{P}$ value & \\
\hline & CONT & SAFF & RPFO & CONT & SAFF & RPFO & B & $\mathrm{D}$ & $\mathrm{B} \times \mathrm{D}$ \\
\hline EPA, C20:5n-3 & 10.49 & 9.39 & 26.36 & 8.92 & 9.45 & 33.47 & 0.259 & $<0.001$ & 0.078 \\
\hline DHA, C22:6n-3 & 6.75 & 2.85 & 8.61 & 5.88 & 3.35 & 10.59 & 0.292 & $<0.001$ & 0.078 \\
\hline cis-9,trans-11CLA & 4.74 & 3.55 & 3.48 & 3.27 & 3.38 & 2.25 & 0.159 & 0.386 & 0.706 \\
\hline
\end{tabular}

Conclusion Provision of a rumen-protected fish oil supplement to heifer calves for 4 months while at pasture was an effective strategy for enhancing muscle EPA and DHA content, whereas provision of a concentrate containing safflower oil had no effect on cis-9, trans-11 CLA abundance in muscle in heifer calves of this age.

Acknowledgements This research was supported by ProSafe Beef, an EU 6 ${ }^{\text {th }}$ Framework Programme project (2007-2012). The donation of the rumen-protected fish oil supplement by the Farmright Group, Ltd., UK is gratefully acknowledged and appreciated. Statistical analysis was performed by Paula Reid, Teagasc, Ashtown, Dublin.

\section{References}

Boles, J.A., Kott, R.W., Hatfield, P.G., Bergman, J.W. and Flynn, C.R. 2005. Journal of Animal Science 83, $2175-2181$. Dinius, D.A., Oltjen, R.R., Lyon, C.K., Kohler, G.O. and Walker, Jr., H.G. 1974. Journal of Animal Science 39, $124-133$. Golay, P.A., Dionsis, F., Hug, B., Giuffrida, F. and Destaillats, F. 2006. Food Chemistry 101, 1115-1120.

Noci, F., Monahan, F.J., French, P. and Moloney, A.P. 2005. Journal of Animal Science 83, 1167-1178.

Nuernberg, K., Nuernberg, G., Ender, K., Lorenz, S., Winkler, K., Rickert, R. and Steinhart, H. 2002. European Journal of Lipid Science and Technology 104, 463-471.

Shingfield, K.J., Ahvenjärvi, S., Toivonen, V., Ärölä, A., Nurmela, K.V.V., Huhtanen, P., Griinari, J.M. 2003. Animal Science 77, 165-179. 